\title{
Dossier Migraciones y Salud Mental
}

\author{
Olga Lucia Huertas Hernández ${ }^{a}$ \\ Pontificia Universidad Javeriana, Colombia \\ ORCID: https://orcid.org/0000-0002-5124-4182
}

a Autora de Correspondencia: olga.huertas@javeriana.edu.co 
Aunque el fenómeno de la movilidad migratoria en el país había estado históricamente relacionado con la salida de colombianos a otros países debido a factores como la violencia sociopolítica, las situaciones de pobreza y/o por la falta de oportunidades económicas para una vida digna y segura, la migración de extranjeros al país era minoritaria. En los últimos años, especialmente desde finales de la década de 1990, se ha registrado un aumento significativo de la población migrante proveniente de países limítrofes tales como Ecuador, Venezuela y Perú.

La población migrante de Venezuela ha tenido un alto impacto en el país, y desde el año 2000 , esta migración ha sido progresivamente masiva y más compleja(1). Actualmente se estima que cerca de 1'770.000 ciudadanos venezolanos han migrado desde Venezuela a Colombia(2). Algunos autores han identificado diferentes olas o periodos en esta migración, que se caracterizan por las razones que motivaron la migración, la población que principalmente se movilizó en un período particular y la cantidad de población que migró. La primera ola se produjo en el año 2000 y estuvo asociada a los cambios generados por el modelo económico promovido por el presidente Hugo Chávez. Primero migraron grandes empresarios y políticos y, luego, con la expropiación y estatización de la industria petrolera y las medidas económicas que generaron una creciente inflación, emigraron profesionales cualificados de diversos sectores y más empresarios. Esta migración no fue masiva ni precaria. Sin embargo, los cambios generados a partir de las medidas económicas y políticas implementadas por el gobierno de Nicolás Maduro desde el año 2013 que propiciaron una crisis económica donde la devaluación de la moneda, así como la persecución política y el cierre temporal de la frontera, produjeron el retorno de colombianos y la migración de ciudadanos venezolanos de distintas condiciones socioeconómicas. A diferencia de las primeras olas migratorias, las últimas han sido masivas $\mathrm{y}$ en condiciones de precariedad(3).

Debido a la variación en las condiciones en que se ha ido dando el fenómeno migratorio de población venezolana, este representa uno de los grandes retos para Colombia a la hora de dar respuesta a una población que enfrenta una crisis humanitaria y que ha sido expuesta a diversas formas de violencia (política, económica y social). El país ha elaborado estrategias para movilizar acciones e instituciones con el fin de atender la crisis humanitaria, como la expedición del Documento CONPES 3950 de 2018. Sin embargo, es claro que no solo se requieren medidas que permitan atender la situación coyuntural de tránsito o emergencia, sino que se requieren otras que además logren dar respuesta a las situaciones que afectan el bienestar psicológico de esta población.

Para comprender la relación existente entre la experiencia de la migración y el surgimiento de un problema en salud mental, se requiere una atención multidimensional que tenga en cuenta las características de las personas, las situaciones previas a la migración, la manera como sucedió la migración y las condiciones de las comunidades receptoras(4). Bajo estas consideraciones, algunos de los problemas asociados con la salud mental en el marco de las condiciones de la migración de población venezolana, están referidos a los efectos psicológicos 
derivados de los duelos por el desarraigo, la ruptura de vínculos familiares y el abandono de sus bienes materiales; el miedo generado por el desconocimiento del entorno, el rechazo por parte de las comunidades receptoras, las violencias existentes en la zonas de acogida o la persecución política; los sentimientos de frustración por el ingreso irregular al país, que limita las posibilidades de empleo seguro e incluso de empleos precarios, la limitada oferta de programas sociales para atender sus necesidades básicas (salud, vivienda y educación) y la dificultad para reconstruir redes de apoyo.

Ante la complejidad de la emergencia, las condiciones de la última ola migratoria y la necesidad de entender que el fenómeno se prolongará en el tiempo, en el país se han generado distintos espacios de diálogo que han permitido profundizar en la relación migración - salud mental, y en la necesidad de avanzar en el planteamiento de recomendaciones para mejorar la respuesta (inmediata) a las necesidades en salud mental y para el desarrollo de una política pública en salud mental que incluya a la población migrante. Dadas las actuales condiciones, es necesario movilizar la atención de respuestas contingentes humanitarias a acciones y programas articulados en políticas públicas, "de forma multidimensional, dinámica y continua, en un marco ético transnacional de los derechos humanos y la equidad en salud pública"(5 p.405).

En el marco de estas inquietudes surgió, por parte del Programa Salud y Migración de la OIMColombia en asocio con la Facultad de Psicología de la Pontificia Universidad Javeriana, el interés de generar un espacio de debate y para visibilizar diversas experiencias nacionales e internacionales que han tratado de entender y atender los impactos en la salud mental en contextos de emergencia y violencia derivados del fenómeno migratorio. Para ello, en agosto de 2019 se llevó a cabo en la Universidad Javeriana el Simposio Internacional Migraciones y Salud Mental que contó con el apoyo de la Universidad del Norte y la participación de líderes de la población migrante, invitados académicos nacionales e internacionales y representantes de organizaciones gubernamentales y no gubernamentales relacionados con la atención en salud de esta población.

Las discusiones realizadas giraron en torno a cuatro aspectos: el entendimiento de la salud mental en un contexto de migración, las afectaciones (positivas y negativas) que generan mayor impacto en la salud mental de la población migrante, los elementos prioritarios en la atención psicosocial a población migrante y los retos que se plantean para elaborar una política pública que atienda las necesidades de atención en salud mental de los migrantes. Este Dossier recupera cuatro de los textos propuestos que esperamos contribuyan a mostrar la necesidad en la atención en salud mental de una política pública que integre a la población migrante, reconozca la urgencia de la articulación transectorial y la importancia de la participación tanto de la población migrante como de las comunidades receptoras. 


\section{Referencias}

1. Banco Mundial. Migración desde Venezuela a Colombia: impactos y estrategia de respuesta en el corto y mediano plazo. 2018, Washington DC: Banco Internacional de Reconstrucción y Fomento. Disponible en: https://openknowledge.worldbank.org/handle/10986/30651

2. Migración Colombia. Infografía venezolanos en Colombia; 2019. Disponible en: https://www.migracio ncolombia.gov.co/infografias/content/259-infografias-2020.html

3. Reina M, Mesa CA, Ramírez T. Elementos para una política pública frente a la crisis de Venezuela. 2018. Cuadernos de Desarrollo 69. Fedesarrollo: Bogotá. Disponible en: https://repository.fedesarrollo.org .co/bitstream/handle/11445/3716/CDF_No_69_Noviembre_2018.pdf?sequence $=1 \&$ isAllowed=y

4. Luna A. Mejía-Arango S. Una propuesta de complementariedad entre los estudios de migración y psicoanalíticos en salud mental. 2019. Estudios Fronterizos, 20, e034. https://doi.org/10.21670/ref. 191303

5. Fernández- Niño J, Navarro- Lechuga E. Migración humana y salud: un campo emergente de investigación en Colombia Editorial. Rev Salud Pública. 2018;20(4): 404-407. https://doi.org/10.15 446/rsap.v20n4.74970

Notas

1 En el marco del proyecto "Fortalecimiento institucional y comunitario para la respuesta en salud para migrantes" financiado por OFDA (Office of Foreign Disaster Assistance, USAID). 